\title{
Study on the Awareness and Practice among Health Care Workers on BMWM in a Teaching Hospital in Nellore, A.P. India
}

\author{
Y. Umarani ${ }^{1}$, D. Sarada ${ }^{2 *}$, P. Sujatha ${ }^{3}$, E. Vandana Giridhar ${ }^{3}$ and M. Raja Rajeswari ${ }^{3}$ \\ ${ }^{1}$ ACSR Govt. Medical College, Nellore, A.P., India \\ ${ }^{2}$ Govt. Siddhartha Medical College, Vijayawada, India \\ ${ }^{3}$ Department of Microbiology, Siddhartha Medical College, Vijayawada, A.P., India
}

*Corresponding author

\section{A B S T R A C T}

\begin{tabular}{|c|}
\hline Keywords \\
\hline $\begin{array}{l}\text { Biomedical waste } \\
\text { management, } \\
\text { Segregation, HCW, } \\
\text { Biohazard symbol, } \\
\text { Evaluation }\end{array}$ \\
\hline Article Info \\
\hline $\begin{array}{l}\text { Accepted: } \\
22 \text { October } 2018 \\
\text { Available Online: } \\
10 \text { November } 2018\end{array}$ \\
\hline
\end{tabular}

Keywords

Biomedical waste

Segregation, HCW

Article Info

Accepted:

Available Online:

10 November 2018
This study was undertaken to determine the awareness regarding biomedical waste management policy and practices, attitude towards biomedical waste management and awareness regarding needle stick injury among different categories of health care workers. The study was conducted using closed ended questionnaire and distributed among 110 individuals in four categories of health care workers. The questionnaire was used to assess their knowledge on biomedical waste disposal. The resulting answers were graded and the number of correct and incorrect answers obtained for each question from individual participants. The results showed that there was a poor level of knowledge and awareness of biomedical waste generation, hazards, legislation and management among health care personnel. Major areas of deficit found were about knowledge regarding number of BMW categories (0\%), definition about biomedical waste (26.6\%) and definition of segregation $(45.7 \%)$ among nursing and other paramedical staff. So, it is necessary for all health care providers to undergo regular training in Biomedical waste management for proper handling and disposal.

\section{Introduction}

Biomedical waste refers to any solid or liquid waste which is generated during the diagnosis, treatment, immunisation of human beings or animals or research activities in hospitals, clinics, laboratories and veterinary institutions, blood banks and health camps. The amount of waste generated under Indian conditions has been estimated as 1 to $2 \mathrm{kgs} / \mathrm{bed} /$ day composed of different types of waste in which an average of about $85 \%$ is harmless and only $15 \%$ is highly infectious and dangerous and could cause serious damage to the society and environment when it is not properly segregated and disposed off.

The government of India has enacted the BMW management and handling rules 1998 in July 1998, BMW rules 2011 and BMW rules 2016 march for environment, forest and climate change under which it is mandatory for all health care facilities to ensure that the BMW be handled and managed without any harm to human health and environment. The success of BMW management programme 
rests on the knowledge and practice of the health care workers.

The aim of the study is to estimate the awareness about BMWM in health care workers (HCW) to minimise cross infection, improve the general hygiene in hospitals and minimise environmental pollution through proper treatment and disposal of waste.

The objectives of the programme are impact of awareness and suggest suitable measures for improving the efficiency of the training.

\section{Materials and Methods}

This study was conducted over a period of six months (Feb 2017 to July 2017) at a tertiary care teaching hospital in Nellore, A.P, South India with 750 beds and an average occupancy of $80 \%$ with 1500 outpatients everyday on an average. About half ton of BMW is generated everyday in the hospital. There are 76 biomedical waste generation and segregation sites in the hospital which included all wards, laboratories, operation theatres, investigation areas and intensive care units under supervision of infection control nurses and quality management team for proper segregation of Biowaste at source. The biowaste is collected daily by safe environment and sanitation (S.S-BW management pvt. Ltd.) from the hospital storage room for disposal to a place located at $14 \mathrm{~km}$ distance.

An interview type of study was conducted at the time of awareness work shop - sanitation policy on BMW Rules 2016 march in February 2017 and July 2017 through a questionnaire comprising of multiple choice questions to test the awareness and practices regarding BMWM. The questionnaire was distributed among four categories of HCWs doctors, nurses, laboratory technicians and other paramedical staff including sanitary supervisors and sanitary workers of the hospital. The overall response of the participants was graded based on correct responses - as satisfactory - more than $70 \%$ intermediate $-50-70 \%$ - and unsatisfactory less than $50 \%$.

\section{Results and Discussion}

A total of $110 \mathrm{HCWs}$ or respondents comprising of doctors-25(22.73\%), nurses$30(27.27 \%)$, lab technicians-20(18.18\%) and other paramedical staff-35(31.82\%) participated in the study (Table 1).

Doctors included in the study were teaching faculty members and senior residents with period of work experience varying from less than 5 years to 10 years among $\mathrm{HCW}$.

This study was undertaken to check the awareness regarding BMW among the hospital staff. An active biomedical waste management committee exists in the hospital which has formulated action plans and guidelines for BMWM and has been circulated to all the departments and displayed at major waste generating areas.

In this study, only $20(22 \%)$ individuals of the HCWs were aware of the number of categories of BMW. This is similar to the finding of Bhagavathi et al., (17\% awareness). This was very poor amongst the L.T. $(0 \%)$ and nurses $(0 \%)$ similar to the finding of Bhagavathi and high in studies by Madhukumar et al., and Mathews et al., $62.5 \%$ and $100 \%$ amongst LTs and nurses and other paramedical staff respectively.

In HCWs (45\%) 46 members had knowledge about the definition of BMW (Table 2) which is similar to the findings of Bhagavathi et al., (47\%) and deshmukh et al., (36.9\%). 
Fig.1 Display of Segregation of Bio-Medical Waste

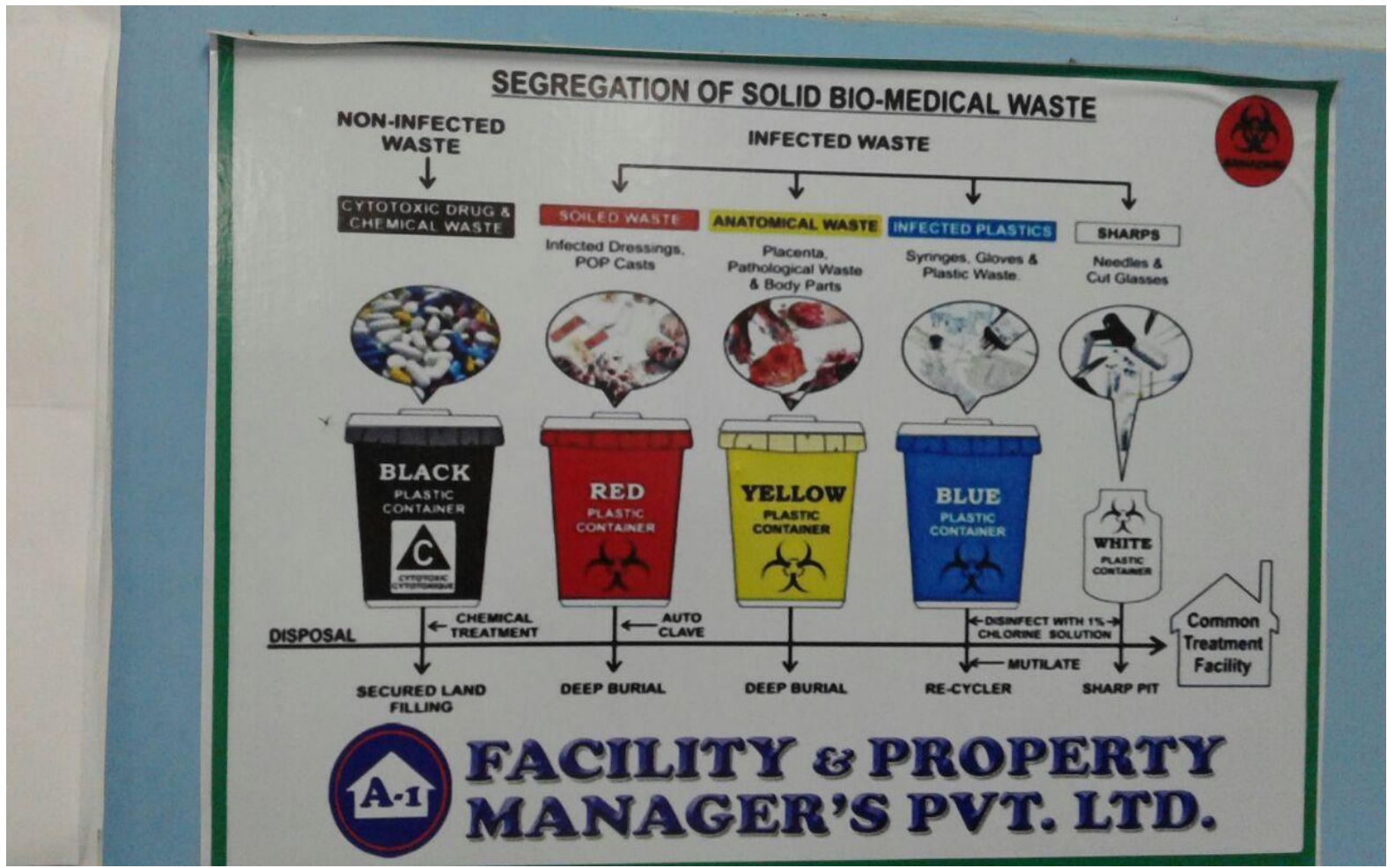

Fig.2 Colour Coded Bins

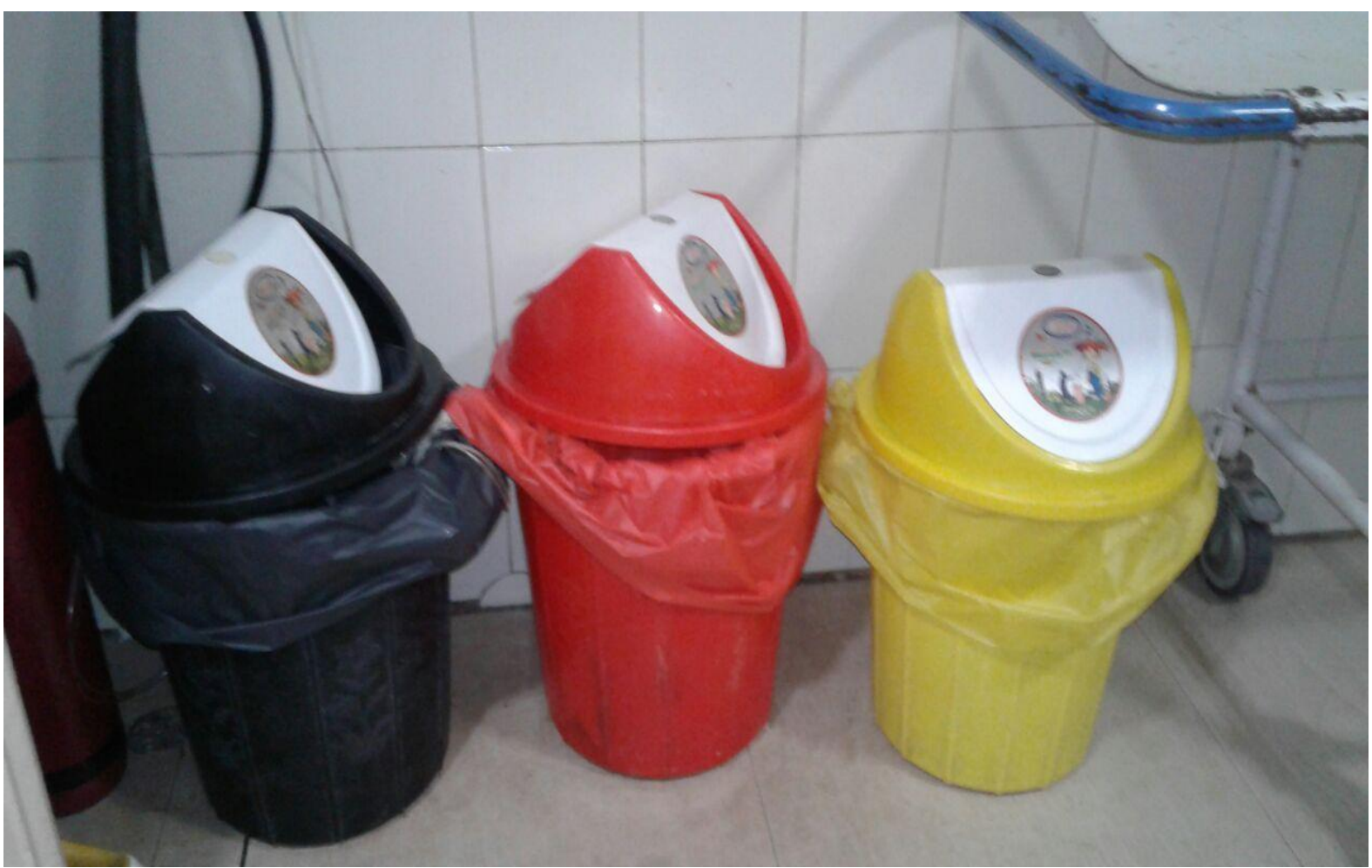


Fig.3 Staff Handling Biomedical Waste

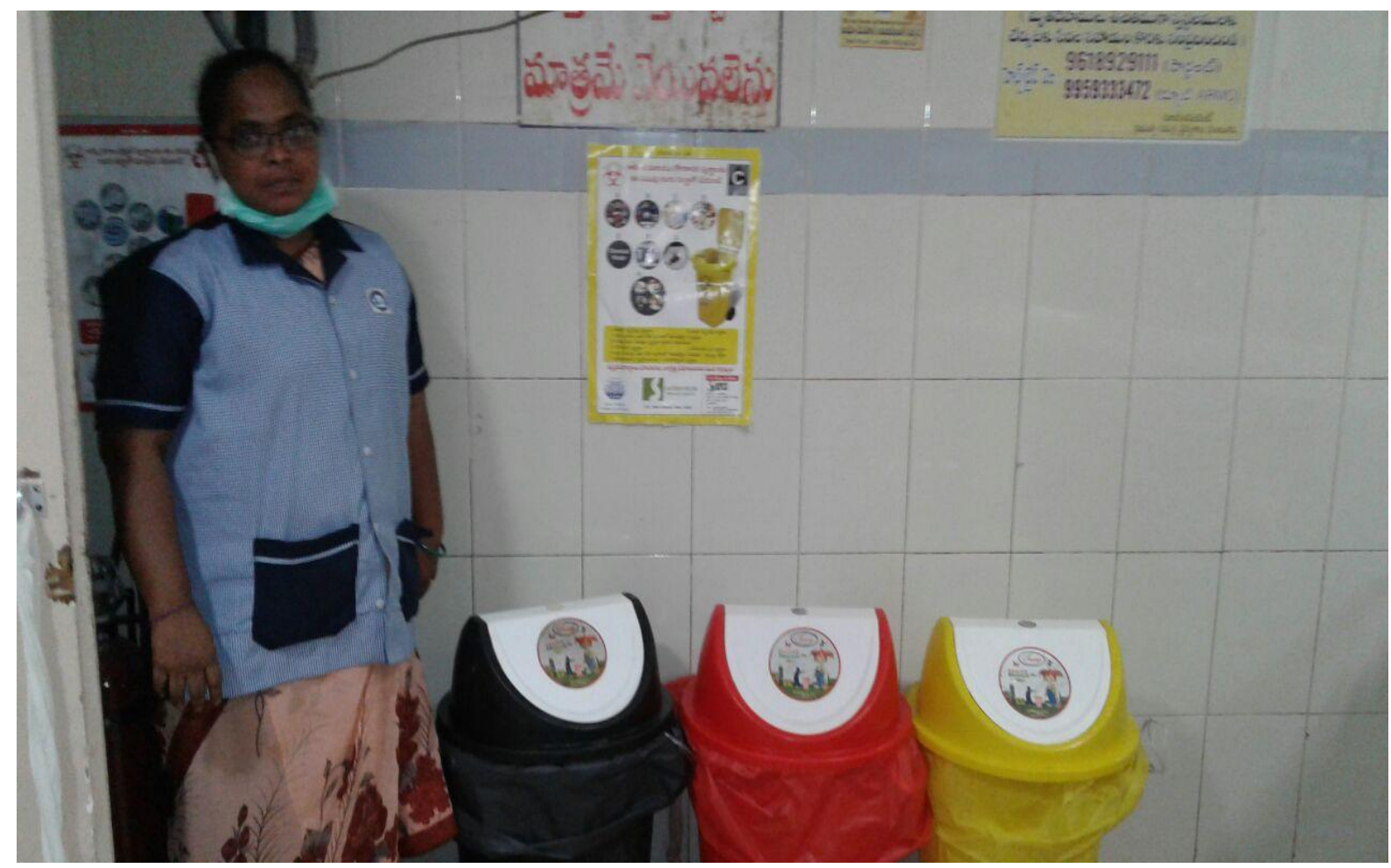

Fig.4 Colour Coded Bags with Biohazard Symbol

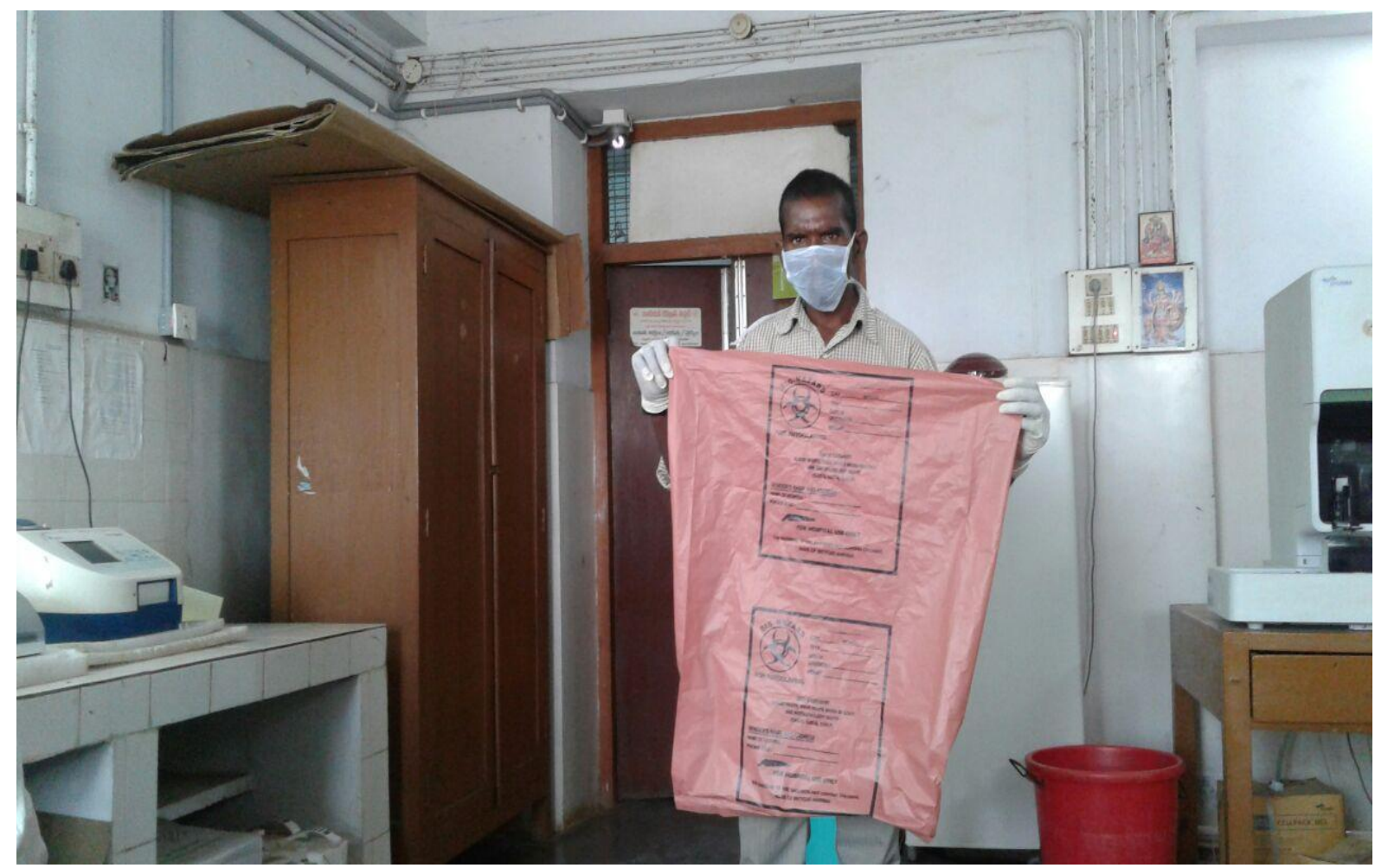




\section{Int.J.Curr.Microbiol.App.Sci (2018) 7(11): 2989-2995}

Table.1 Categories of health care workers and number of participants

\begin{tabular}{|c|l|l|}
\hline S. No. & Category & Number \\
\hline 1. & Doctors & 25 \\
\hline 2. & Nurses & 30 \\
\hline 3. & Lab technicians & 20 \\
\hline 4. & Other paramedical staff & 35 \\
\hline Total & & 110 \\
\hline
\end{tabular}

Table.2 Awareness regarding BMWM amongst various HCWs in \%

\begin{tabular}{|c|c|c|c|c|c|c|c|c|c|c|c|c|c|c|c|}
\hline 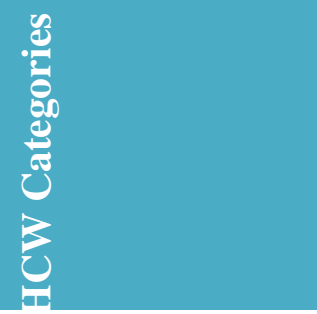 & $\begin{array}{l}\frac{3}{8} \\
\frac{8}{2} \\
\sum_{\infty}^{*} .\end{array}$ & $\sum_{0}^{3}$ & 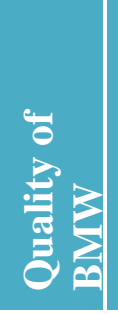 & 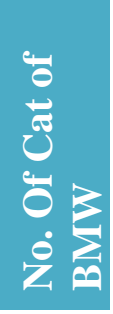 & 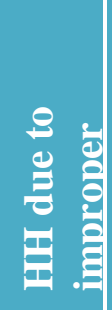 & 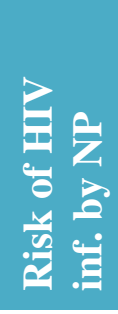 & 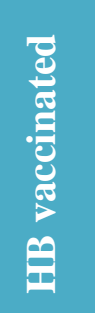 & 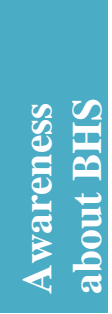 & $\sum_{\substack{E \\
巳}}^{E}$ & 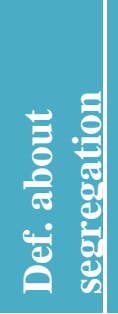 & $\begin{array}{l}\frac{5}{3} \\
\frac{8}{8} \\
\frac{2}{2} \\
\frac{0}{8} \\
\frac{3}{2} \\
\frac{8}{Z}\end{array}$ & 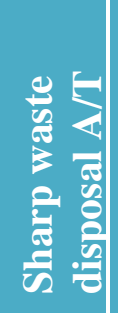 & 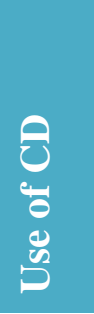 & 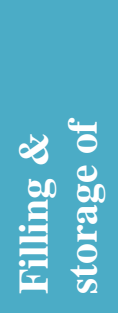 & 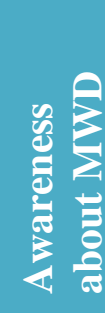 \\
\hline Doctors (25) & 80 & 72 & 36 & 52 & 100 & 100 & 100 & 88 & 88 & 56 & 80 & 96 & 72 & 52 & 40 \\
\hline Nurses (30) & 93 & 26.6 & 20 & 0 & 15 & 86.6 & 93.3 & 83.3 & 16.6 & 66.6 & 80 & 76.6 & 66.6 & 83.3 & 10 \\
\hline Technicians (20) & 90 & 50 & 30 & 0 & 50 & 100 & 100 & 90 & 90 & 80 & 90 & 90 & 90 & 30 & 20 \\
\hline $\begin{array}{l}\text { Other } \\
\text { paramedical } \\
\text { staff( }(35)\end{array}$ & 80 & 28.6 & 17.1 & 20 & 51.4 & 51.4 & 97.1 & 85.7 & 94.2 & 45.7 & 51.4 & 91.4 & 80 & 71.4 & 20 \\
\hline
\end{tabular}

Table 2: Def.: Definition, Qnty: Quantity, No.: Number, Cat: Categories, H.H.: Health Hazards, HBV: Hepatitis B vaccine, NP: Needle Prick, BHS: Biohazard Symbol, NSW: Non-sharp waste, A/T: according to, CC: Colour coding, CD: Chemical disinfectants, MWD: Mercury waste disposal. 
Overall response based on guidelines laid by Government of India for BMWM was satisfactory (80\%) (Table 2).

Awareness regarding biohazard symbol was satisfactory 96 members $(87.27 \%$ ) (Table 2) and similar to the findings of Madhukar et al., and Bhagawathi et al., (91\%).

Awareness regarding Health hazards due to improper BMWM was found to be $57.28 \%$ (Tab.II) in our study. Awareness among Doctors was $25(100 \%)$ as reported similarly by Narang et al., (100\%) which was in contrast to the finding of Bhagawati et al., $(63.46 \%)$.

In our study overall response regarding the disposal of non sharp waste (NSW) was 78 (70.99\%) (Tab.II) and sharps was 97(88.8\%). Awareness among doctors was $24(96 \%)$ and $20(80 \%)$ followed by LTs $18(90 \%)$ and $18(90 \%)$ and nurses $24(80 \%)$ and $23(76.66 \%)$ respectively. This was similar to the study of Bhagawati et al.,

Awareness regarding segregation among HCW was $61.88 \%$ (68) and among doctors was $14(56 \%)$. This was in contrast to the finding of Nandavani et al., (82\%) in HCW and study by Selvaraj et al., awareness in doctors is $98 \%$. In our study the above findings were similar to the findings of $\mathrm{G}$ Bhagawati et al., $53.7 \%$ and $57.7 \%$ in $\mathrm{HCW}$ and doctors respectively. The reason for the same could be overload of work in O.P. departments in Government set up for more patient care than waste segregation. Awareness in mercury waste disposal amongst four categories of HCWs is: doctors$40 \%$, lab tech. and paramedical and staff nurses- $10 \%$.

Knowledge of effective management of Biomedical waste is essential in persons who generate the waste, not just who handle it.
BMWM requires conducting trainings and workshops for health care providers to prevent improper handling, transportation and disposal which can be helpful to minimise the cause of infection effectively. There is an urgent need for raising awareness on BMWM among the hospital staff in all health care setups. Involvement of hospital administrators and regular appraisal with the status of BMWM in waste management and quality steering committee play a pivotal role in executing the policies effectively.

\section{References}

Bhagawati, G., S Nandwani, S Singhal. Awareness and practices regarding biomedical waste ma nagement among health care workers in a tertiary care hospital in Delhi. Indian $\mathbf{J}$ Med Microbiol 2015; 33(4):580-582.

Biomedical waste management in Delhi. Available from: http://dpcc.delhigovt. nic.in/bio-medical-waste.html.

Biomedical waste management. Available

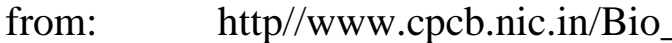
medical.php.

Joseph, L., H Paul, J Premkumar, Rabindranath, R Paul, JS Michael. Biomedical waste management: Study on the awareness and practice among healthcare workers in a tertiary teaching hospital. Indian $\mathbf{J}$ Med Microbiology 2015; 33(1): 129-131.

Joshi SK. Quality Management in Hospitals. Ch. 43. Bio-medical waste management program. New Delhi. Jaypee Publications; 2009.

Kumar, A., S Duggal, R Gur, SR Rongpharpi, S Sagar, M Rani, D Dhayal, CM Khanijo. Safe transportation of biomedical waste in a health care institution. Indian $\mathbf{J}$ of Med Microbiology. 2015; 33(3):383-386.

Madhukumar S, Ramesh G. Study about awareness and practices about health 
care waste management among hospital staff in a medical college hospital, Bangalore. Int J Basic Med Sci 2012; 3: 1.

Mathew SS, Benjamin AI, Sengupta P. Assessment of biomedical waste management practices in a tertiary care teaching hospital in Ludhiana. Healthline 2011; 2: 28.

Mathur P, Patan S, Shobhawat S. Need of biomedical waste management system in hospitals - an emerging issue - A review. Curr World Environ 2012; 7: 117-24.

Nandwani S. Study of biomedical waste management practices in a private hospital and evaluation of the benefits after implementing remedial measures for the same. J Commun Dis 2010; 42: 39-44.

Narang RS, Manchanda A, Singh S, Verma N, Padda S. Awareness of biomedical waste management among dental professionals and auxiliary staff in Amritsar, India. Oral Health Dent Manag 2012; 11: 162-8.
Notification on Bio-Medical Waste (Management and Handling) Rules. New Delhi: The Gazette of India; 1998.

Saini S, Nagarajan SS, Sarma RK. Knowledge attitude and practices of bio-medical waste management amongst staff of a tertiary level hospital in India. J Hosp Adm 2005; 17: 2.

Selvaraj K, Sivaprakasam P, Nelson SB, Kumar GH, Norman P, Pandiyan KR. Knowledge and practice of Biomedical Waste (BMW) Management among the medical practitioners of Kanchipuram Town, India. Int J Curr Microbiol Appl Sci 2013; 2: 262-7.

Sharma R, Rasania SK, Verma A, Singh S. Study of prevalence and response to needle stick injuries among health care workers in a tertiary care hospital in Delhi, India. Indian J Community Med 2010; 35: 74-7.

Usha Krishnan, K., T Sheila Doris Devamani, G Jayalakshmi. On the path of continual improvement: An evaluation of biomedical waste management training. Indian J Med Microbiology 2015: 33(supplement 1): S119-2.

\section{How to cite this article:}

Umarani, Y., D. Sarada, P. Sujatha, E. Vandana Giridhar and Raja Rajeswari, M. 2018. Study on the Awareness and Practice among Health Care Workers on BMWM in a Teaching Hospital in Nellore, A.P. India Int.J.Curr.Microbiol.App.Sci. 7(11): 2989-2995.

doi: https://doi.org/10.20546/ijcmas.2018.711.343 